\section{Effect of repeated testing on development of visual acuity in prairie deermice} (Peromvscus maniculatus bairdi)*

\author{
BEDFORD M. VESTAL† and JOHN A. KING
}

Michigan State University, East Lansing, Mich. 48823

The pattern of development of visual acuity in deermice was determined by elicitation of optokinetic responses. The mice were tested either cross-sectionally (each individual tested only once) or longitudinally (individuals tested repeatedly) after eye opening. Development of acuity was significantly accelerated by the repeated testing procedure.

The developmental rate of sensory systems determines the rate at which a young animal is exposed to new stimuli. This rate of exposure could in turn modify both the rate of development of the sensory system itself as well as related behaviors (King, 1967). The interaction of the developmental rate and the rate of exposure to external stimuli provide the basis for the formation of adult behavior.

During the procedure of measuring sensory development, the rate of development may be altered. Studies of developmental patterns typically involve either repeated measures of the same individual over time (longitudinal measure) or measures of independent groups at each age (cross-sectional) (King, 1969). Longitudinal groups can be affected by the repeated measuring procedure, whereas cross-sectional groups are exposed to the procedure only once.

Experiential modification of the developmental patterns of sensory modalities is possible. Development of auditory responses of ducklings has been delayed and accelerated by withholding or augmenting auditory stimulation (Gottlieb, 1971a). Although visual deprivation can decelerate the rate of visual development, acceleration of the developmental rate by stimulus augmentation has not been well documented (Gottlieb, 1971b). In a strain of prairie deermice which had been genetically selected for early age of eye opening, the onset of functional pattern vision did not occur before the age of normal occurrence in wild-type mice, in spite of the opportunity for

*This research was supported by NIH Training Grant No. GM-01751 and Research Grant EY-0447. Kristi Dege and Laurel Garrety provided valuable technical assistance.

+Present address of Bedford Vestal is Department of Biology, University of Missouri-St. Louis, 8001 Natural Bridge, St. Louis, Mo. 63121 . Requests for reprints should be sent to Vestal. added visual experience (Vestal \& King, 1968). The visual experience would have had no effect if the animals could not see at this early age. The purpose of this study is to determine the effect of repeated exposure to the testing procedure on the rate of d e velopment of visual acuity in prairie deermice (Peromyscus maniculatus bairdi).

\section{METHOD}

The Ss were prairie deermice, Peromyscus maniculatus bairdi, which inhabit midwestern grasslands of the U.S. This subspecies is terrestrial in its habits (Howard, 1949) and behavior (Horner, 1954). All mice used in this study were born and raised in the laboratory at Michigan State University. They were first to fourth generation descendants of wild animals trapped in the vicinity of Lansing, Mich.

The developmental period which was examined included the day of eye opening (Day 0 ) and Days $1,2,3,4,5$, 6 , and 8 after the day of eye opening. In the cross-sectional group, 10 mice ( 5 males and 5 females) were tested at each age level after eye opening (total of 80 mice). Each mouse was tested only once (Vestal, 1970). The longitudinal group consisted of 20 mice (10 males and 10 females), with all of the mice tested at each age level over the developmental period.

Visual acuity was determined by use of the optokinetic response. The response is functional at the age of eye opening in deermice (Vestal \& King, 1968) and has been used in other developmental studies (see Vestal, 1970 , for review ).

The optokinetic device used to elicit the response was a rotatable wooden disc on which an upright aluminum cylinder of $40-\mathrm{cm}$ radius could be mounted. The device was rotated by a reversible variable-speed electric motor. Mlumination was provided by an incandescent lamp mounted in a metal reflector with sheets of white paper to diffuse the light. Light intensity was 86.1 lux as measured at the position of the Ss in the apparatus.

The visual stimuli were interchangeable striped panels lining the metal cylinder. Photographs of vertical black and white stripes of equal width were glued to sheets of heavy paper to form the cylinder lining panels. Stripes for the $40-\mathrm{cm}$ drum ranged from 14 to $140 \mathrm{~min}$ of arc in $7-\mathrm{min}$ increments and additional stripes subtending 203 and $266 \mathrm{~min}$ of arc. A gray paper panel was used in control trials.

The Ss were restrained on a platform attached to a central shaft which was independent of cylinder motion. Stripes $2 \mathrm{~mm}$ apart on the platform provided a ruled background against which movements of the S's head could be viewed. S's head and forequarters were free to move, and the center of the mouse's head was aligned over the center of the drum before each trial.

Mice were from litters of three to five young. From 10 days of age, litters were checked daily for eyelid separation. No more than two mice from any litter were used in any experimental cell. Testing was scheduled by a code system to avoid $\mathrm{E}$ bias for age of the mice.

After 1.2 min of adaptation, testing began with stripes of the largest width. Rotation of the drum began when the mice were alert with no fixed intertrial interval. Direction of rotation was reversed for each trial, and most tests were run between 2.5- and 6-rpm speed.

The mice were given eight trials of $15 \mathrm{sec}$ duration with one stripe width unless they responded before eight were completed. An optokinetic

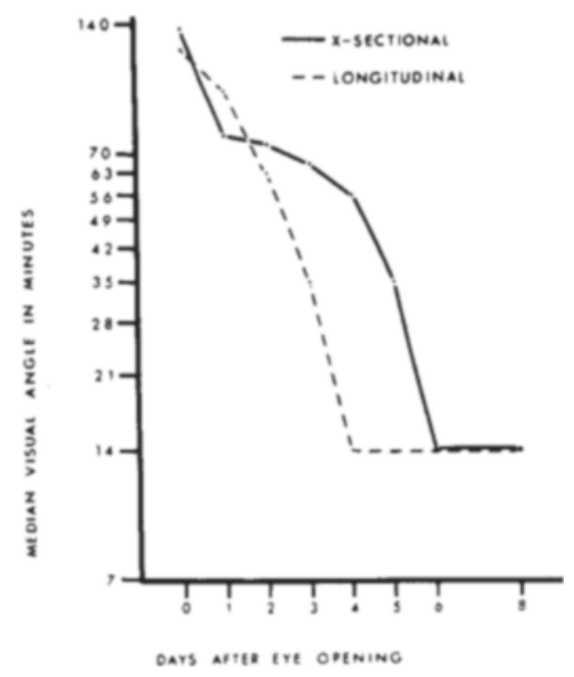

Fig. 1. Median visual angle in minutes of arc on each day after eye opening. The smallest stimulus angle was $14 \mathrm{~min}$ of arc. 
Table 1

Cumulative Percentage of Animals Responding to 14-Min Stripes at Each Age

\begin{tabular}{cccccccccc}
\hline & \multicolumn{7}{c}{ Age in Days After Eye Opening } \\
\cline { 2 - 9 } & 0 & 1 & 2 & 3 & 4 & 5 & 6 & 8 \\
\hline $\begin{array}{c}\text { Cross-Sectional } \\
(\mathrm{N}=10) \\
\begin{array}{c}\text { Each Age } \\
\text { Longitudinal } \\
(\mathrm{N}=20)\end{array}\end{array}$ & 0 & 0 & 0 & 0 & 10 & 30 & 80 & 90 \\
\hline
\end{tabular}

response was recorded for either one clear head movement crossing at least two lines on the platform or two clear eye responses. Criterion of response to a given stripe width was an optokinetic response during at least one trial in each direction of rotation.

If a mouse responded to the larger stripes, smaller stripes were inserted until the $S$ failed to reach criterion. Stripe size was then increased in increments of $7 \mathrm{~min}$ of arc until the mouse responded again. The smallest stripe width to which a mouse responded was designated as its minimum visual angle. Six mice given control tests with a solid gray drum did not respond but did respond to striped drums before and after the control tests.

Observer reliability was calculated by the percentage of agreement between two independent Os on presence or absence of an optokinetic response during a trial. On 327 trials with 15 mice, there was $93 \%$ agreement between Os. RESULTS

Scores of the two groups on each day were compared by nonparametric Mann-Whitney $U$ tests (Siegel, 1956) because of the large number of responses to the smallest stimulus angle $(14 \mathrm{~min}$ of arc). Results of a parametric analysis of variance comparing the groups on Days 3,4 , and 5 are consistent with those of the $\mathrm{U}$ tests.

The two treatment groups did not differ in median size of minimum visual angle on Days $0,1,2,6$, and 8 . The visual angles of the longitudinal group were significantly lower (p $<.02$; Mann-Whitney U, Siegel, 1956) than those of the cross-sectional group on Days 3,4, and 5 (Fig. 1). More individuals of the longitudinal group responded to the 14-min stripes, which were the smallest used for testing, than did those of the cross-sectional group (Table 1). The actual adult visual acuity threshold is lower than $14 \mathrm{~min}$ (King \& Vestal, unpublished data), so that $14 \mathrm{~min}$ represents an artificial cutoff point.

$$
\text { DISCUSSION }
$$

After 3 days of testing, the median scores for the longitudinal animals were lower, and greater numbers of longitudinal mice responded to the smallest stimulus angle than did cross-sectional mice. In the cross-sectional group, changes were relatively slow from Day 1 through developed more during these days, which resulted in the cross-sectional group's being about 2 days behind the longitudinal group in the reduction of the visual angle.

Several explanations are possible for the acceleration of the longitudinal group. Repeated testing may have accelerated development either through handling the young animals or by providing them extra visual experience. A handled control group without visual experience would differentiate the effects of these two factors. Handling might accelerate maturation of the sensory system, as it accelerated eye opening in cats (Meier, 1961).

The alternative explanation, that the accelerated development resulted from visual experience, is strengthened by the observation that young mice normally stay in the nest 3 to 4 days after eye opening. They huddle inside the cotton nest and are exposed to relatively few visual stimuli, even though they are capable of seeing. Their first exploration outside the nest is correlated with the age at which the developmental curve of the cross-sectional mice changes most rapidly (between Days 3 and 5 after eye opening). The mice in the longitudinal group were taken out of the nest daily and exposed to the sights of the experimental room and the test stimuli. This added visual experience may have accelerated development of acuity, thus contributing to the difference between the two groups. The effect of visual Days 3 or 4 . The longitudinal group experience could be examined by either preventing or insuring exposure of the young mice to visual stimuli prior to the age when the developmental curves diverge in the two groups.

This study illustrates the advantage of examining changes of the sensory capacity throughout the entire course of development rather than at one or two points in the developmental curve. The resuits of our cross-sectional group provided a quantitative measure of change in the development of visual acuity. Comparisons of this curve with that of the longitudinal group indicate the extent to which the developmental rate can be modified by experience. The difference in these rates indicate that perceptual learning (Gibson, 1969) may have occurred through repeated exposure to visual stimuli.

\section{REFERENCES}

GIBSON, E. J Principles of perceptual development. New York: Appleton-Century-Crofts, 1969.

GOTTLIEB, G. Development of species identification in birds. Chicago: University of Chicago Press, 1971 a.

GOTTLIEB, G. Ontogenesis of sensory function in birds and mammals. In $\mathrm{E}$ Tobach. (Ed.), Biopsychology of development. New York: Academic Press, 1971 b. Pp. 67-128.

HORNER, B. E. Arboreal adaptations of Peromyscus with special reference to the tail. Contributions of the Laboratory of Vertebrate Biology, University of Michigan, 1954,61, 1-84.

HOWARD, W. E. Dispersal, amount of inbreeding, and longevity in a local population of deer-mice on the George Reserve, Southern Michigan. Contributions of the Laboratory of Vertebrate Biology, University of Michigan, 1949,43, 1-52.

KING, J. A. Behavioral Modification of the gene pool. In J. Hirsch (Ed.), Behavior-genetic analysis. New York: McGraw-Hill, 1967. Pp. 22-43.

KING, J, A. A comparison of longitudinal and cross-sectional groups in the development of behavior of deer mice. Annals of the New York Academy of Sciences, 1969, 159,696-709.

MEIER, G. W. Infantile handling and development in Siamese kittens. Journal of Comparative\& Physiological Psychology, 1961, 54, 284-286.

SIEGEL, S. Nonparametric statistics for the behavioral sciences. New York: McGraw-Hill, 1956.

VESTAL, B. M. Development of visual acuity in two species of Peromyscus (Rodentia). Unpublished doctoral dissertation, Michigan State University, 1970.

VESTAL, B. M., \& KING, J. A. Relationship of age at eye opening to the first optokinetic response in deermice (Peromyscus). Developmental Psy chobiology, 1968, 1. 33-34. 